\title{
The Future of Citizenship: Global and Digital - A Rejoinder
}

\author{
Liav Orgad
}

This has been an insightful discussion that touches upon some of the most fundamental concepts in political theory - communities, states, citizenship, and sovereignty. New technologies challenge the meaning and essence of these terms and blur the lines between physical and digital, local and global. The nature of the transformation is still a puzzle, but sooner rather than later the 'Fourth Industrial Revolution' will reach the institution of citizenship. The possible effects are promising but, as this GLOBALCIT debate shows, scary too.

My celebration of the potential of blockchain technologies to advance the idea of global citizenship lost in the GLOBALCIT digital agora, at least if we count 'votes.' There are four firm supporters (Primavera De Filippi, Francesca Strumia, Dora Kostakopoulou, Ehud Shapiro), five strong objectors (Robert Post, Michael Blake, Peter Spiro, Lea Ypi, Dimitry Kochenov), and five people who are somewhere in between, acknowledging the potential yet expressing concerns (Rainer Bauböck, Costica Dumbrava, Yussef Al Tamimi, Jelena Dzankic, Stefania Milan). The objections are wide - theoretical and practical, empirical and normative, methodological and conceptual. The idea of blockchain-based global citizenship, which can lead to the development of cloud communities that seek to take part in international decision making, is seen as 'techno-utopianism' (Milan), 'escapism' (Kochenov), and 'exclusion[ary]' (Ypi), a risk to 'territorial democracy' (Bauböck) that may bring a 'world without law' (Post) and 'legitimate coercion' that is so essential for the protection of human rights (Blake).

My kick-off had several premises. When discussing the need for an international legal persona for all human beings, I indicated three fundamental problems: human rights concerns (1.1 billion people do not have an official identification), lack of self-governance (individuals have no direct voice in

The research is supported by the European Research Council (ERC) Starting Grant (\# 716350). 
international law-making), and unequal representation (the principle of 'onestate, one-vote' leads to disparities in individual voting power). I identified three developments - the rise of global interconnectedness, identity, and responsibility - that, taken together, can end up with the creation of an international legal persona and digital identity (as a form of 'global citizenship'), thereby mitigating some of these problems. I also indicated one possible outcome of global citizenship - the emergence of (top-down and bottom-up) decentralised 'cloud communities' in which global citizens, sharing a common bond, can be politically organised and collaborate with the purpose of influencing international decision making and, eventually, becoming part of it. The authors in this debate have not addressed the premises, yet challenged my observations (e.g., global interconnectedness) and my conclusion - the potential of global digital citizenship to do more good than harm. I cannot do justice to all the subtle replies, so let me first express my gratefulness to the participants - this has been enriching experience, although it has not changed my optimistic view - and briefly address below some issues that I see as central.

\section{Cloud computing}

A large percentage of humanity is already engaged with some forms of cloud computing on a daily basis. Whenever you use Google Drive, Apple iCloud, and Dropbox, you spend time 'in the cloud.' Whenever you use audio and video streaming, online storage, and mobile services, you are 'in the cloud.' Government services, research data, medical records, and consumer services are available 'in the cloud.' Social networks too are 'in the cloud.' I have never physically met most of the authors who contributed to this debate, but I meet them on a daily basis on Facebook. The reason why we call these digital structures 'cloud' is not due to the lack of territory - the hardware is located somewhere - but because territory is largely irrelevant for the user and the service.

Cloud computing does not create, in and of itself, a 'community' (Post, Spiro), let alone a political community (Blake). Facebook is a social network, not a political community. It is commercial and dictatorial - members have no common bond and cannot create law or engage in governance - and it does not guarantee a truthful unique identity. Yet, in recent years there have been attempts to create cloud-based 'communities' by using blockchain and other technologies. This started as private initiatives, such as Bitnation, but spread into government initiatives, as illustrated by Estonia's e-residency. True, e-Estonia is far from creating a 'community'; Estonia's e-residents do not interact with one another or cooperate for political purposes. They are a group of clients more than a sovereign. It is also true that the notion of DBVNs (Decentralized Borderless Voluntary Nations), where anyone can build a 'community' in a Pangea jurisdiction - an IKEA-style do-it- 
yourself nation - is unrealistic and undesirable. Still, the idea of a political community in which territory is largely irrelevant for certain political functions is worth considering. Thus far, it has been regarded as radical because it was promoted by anarchists and like-minded people looking for disruptive technologies to replace the nation-state. But as technology becomes more developed, it is just a matter of time until the idea will crystallise.

\section{Political community}

Even if the idea crystallises, can we really call cloud networks a 'political community,' or would they be like a 'community of video gamers,' to use Spiro's analogy, or just an addition to global civil society (Bauböck, Post, Milan)? The essence of the community I envision is indeed political, having members who share a common bond (say, the protection of animal rights) and seek to become part of national (and mainly international) decision making. There are similarities between cloud communities and global civil society (Bauböck, Post, Milan) as they are both voluntary, political in nature, civil (in the sense of non-governmental), and usually non-profit. But there are some differences. The global civil society is not composed of sovereign political entities where decision making is based on a 'one person, one vote' principle; global civil society organisations are acting on behalf of a group, while decentralised cloud communities can form themselves democratic collectives acting on a global scale.

Do cloud communities merit being called 'political communities'? It depends on the nature of such a community and how it will be developed. At least three components should come together: 1) members should have a self-perception as belonging to a collective entity, a shared consciousness of forming a political community; 2) members should have political relations and act with a collective responsibility; 3 ) members should be capable of acting collectively with regard to some functions. Take immigrants, for example. If all international migrants - more than 250 million people in 2017 -joined a virtual community, it would be the world's fifth largest 'country' (after China, India, USA, and Indonesia). It could act as a self-governed collective at the international level, negotiating with states and UN agencies, collecting taxes, and promoting immigrant rights worldwide - all based not on representatives or NGOs, but on direct decision-making by its members.

\section{Digital coercion}

What about coercion - how can there be a political community without a recourse to force (Bauböck, Post, Blake, Dumbrava)? Normatively, the coercive force of law can be independent of the state or its territory; it 
requires authority. Such authority exists also in a blockchain-based community with one main difference - it is decentralised. If, for example, the 'migrant cloud community' decides collectively to stop migration to a certain country that does not respect migrants' rights or to buy products from certain retailers, and a migrant who is a member violates the rules, $\mathrm{s} / \mathrm{he}$ can be sanctioned (through fines, suspension, limited access to rights/data, or termination of membership). As long as membership provides some benefits, particularly the ability to influence and shape decisions that affect the member's life, these sanctions are not minor or trivial.

Technologically, since membership is virtual, coercion is realised via software. As Shapiro notes, one's virtual identity (or 'global persona') is programmed to obey the community's decisions ('coercion is achieved through design and programmability, without violence'). In fact, state laws represent 'weak coercion'; there are papers that set rules (e.g., a prohibition of murder or crossing a red light) and one decides whether to follow the rules or violate them, in this case there are punishments and sanctions. Internet protocols are one step further. They are a form of 'strong coercion'; internet codes (e.g., restrictions and blockings) are stronger than papers because the law of the software is more difficult to violate - it is not in the discretion of an individual but requires knowledge and effort. A digital society represents a form of 'absolute coercion.' Transaction monitoring (e.g., voting, tax, or registry) is governed by blockchain rules that one cannot violate.

Socially, 'punishment' in a digital society is of a different type. A person cannot be sent to jail, but her reputation can be discredited. In the digital era, reputation capital is a valuable asset and a factor for providing services and products (think of Airbnb, Uber, eBay). In other words, online reputation has a real-world value. As Al Tamimi observes, 'A punishment in terms of such social devaluation imposed by the cloud state is conceivably more painful and restricting to the individual than traditional methods of punishment, such as fines or jail.'

\section{Functional sovereignty}

The territorial dimension of states has been seen central to citizenship (Bauböck, Post, Blake). Indeed, territory is considered the state's most characteristic feature; states are, by definition (Article 1, Montevideo Convention, 193311), territorial units. Territory is considered necessary for assuming most of the normative functions of the state - for instance, as a source of security and identity,

Available at http://avalon.law.yale.edu/20th_century/intam03.asp 
and for managing natural resources. Against this background, the concept of a deterritorialised state - or cloud communities that would replace the state and fulfil all of its functions - is politically inconceivable. But this does not entail that none of the state's essential functions can be reconceptualised. Cloud communities are not a state-replacement, but an improvement - they seek to add a circle to the already dynamic and multi-layered rich dimensions of citizenship. They are not supposed to act in the physical world - and thus have no sovereignty on issues like murder (Post) - but to govern the transaction of values or data that exist in the digital world (voting, registries, certificates, etc.). However, as cloud communities become politically more important, what happens there will not remain confined to the cloud but influence real-world political decision-making.

The idea of 'concentric circles' of citizenship - to use Cicero metaphor with each circle having a different normative function, is not foreign to the theory of sovereignty. There are three options: cloud communities can be seen as sub-sovereign entities, semi/quasi-sovereign entities, or functional sovereign entities. Let me focus on the third option - functional sovereignty. Under this approach, sovereignty is divided by functions, with each being governed by a different entity. Think of federal systems, a condominium of states, mandate/trusteeship, autonomy (e.g., Quebec or Puerto Rico), or municipalities (where certain functions are governed by local sovereignty). Divisible sovereignty can be exercised over territories - e.g. Andorra, which was a condominium before independence in 1993 and still had two heads of state (the French president and a Catalan bishop) - or peoples. Sovereignty can be divided between political entities, as in federations or in the European Union, or between political and nonpolitical entities - think of religion (in Israeli law, for example, religious law is sovereign in family issues). The idea of functional sovereignty, as coined by Willem Riphagen in $1975,{ }^{2}$ enables entity $A$ to have sovereignty over social welfare, entity $B$ to be the sovereign on financial issues, and entity $C$ to enjoy sovereignty over security - all in the same territory. It also makes it possible for different political authorities to exercise functional sovereignty over different peoples in the same space. The switch is from a jurisdiction over territories to a jurisdiction over functions, peoples and services. As this is not a new concept, we can understand how it could be applied to blockchain-based cloud communities as well.

The normative functions of cloud communities remain an open question in the debate. My focus has been on global topics - global warming, the

2 Riphagen, W. 1975. 'Some Reflections on Functional Sovereignty', Netherlands Yearbook of International Law 6: 121-165. 
environment, and other issues of global sustainability - but it is for the states to decide which functions to delegate to self-sovereign communities. Ultimately, states would set the boundaries and decide the sensitive areas in which sovereignty cannot/should not be divided or shared.

\section{Coda}

We can construct theoretical models of digital citizenship but, as this debate has shown, there are plenty of uncertainties - political, technological, and psychological ones - before it can become actually operative. I agree with Milan that 'much work is needed . . before we can proclaim the blockchain revolution.' In particular, I share the concern about global inequality generated by ideas of cloud communities due to lack of internet access (Dzankic, Ypi, Kochenov) - this gap, however, has tremendously (and rapidly) narrowed and in 104 states more than 80 per cent of the youth population (aged 15-24) are now online. The situation will further improve if a right to internet access is universally recognised. And I cannot but share Bauböck's worries about the tyranny of the majority in the cloud - addressing it is a matter of constitutional design of voting mechanisms (note, however, that there will be judicial review, decisions that require supermajority, and perhaps even veto rights in the digital world as well). Discussing these (and others) concerns will keep theorists and policy makers busy in the years to come. While the focus of this debate is on global citizenship and virtual communities, I see it as a broader invitation to reflect on the nexus between new technologies and the future of citizenship.

Open Access This chapter is licensed under the terms of the Creative Commons Attribution 4.0 International License (http://creativecommons.org/licenses/by/4.0/), which permits use, sharing, adaptation, distribution and reproduction in any medium or format, as long as you give appropriate credit to the original author(s) and the source, provide a link to the Creative Commons license and indicate if changes were made.

The images or other third party material in this chapter are included in the chapter's Creative Commons license, unless indicated otherwise in a credit line to the material. If material is not included in the chapter's Creative Commons license and your intended use is not permitted by statutory regulation or exceeds the permitted use, you will need to obtain permission directly from the copyright holder. 